\title{
Toll-like receptors and cancer, particularly oral squamous cell carcinoma
}

\author{
Alison Mary Rich ${ }^{1}{ }^{*}$, Haizal Mohd Hussaini ${ }^{2}$, Venkata P. B. Parachuru ${ }^{1}$ and Gregory J. Seymour ${ }^{1}$ \\ 1 Faculty of Dentistry, Sir John Walsh Research Institute, University of Otago, Dunedin, New Zealand \\ ${ }^{2}$ Faculty of Dentistry, Department of Oral Pathology and Oral Medicine, National University of Malaysia, Kuala Lumpur, Malaysia
}

\section{Edited by:}

Anahid Jewett, University of

California, Los Angeles, USA

\section{Reviewed by:}

Ruipeng Wang, National Institutes of Health, USA

Eliana Ruggiero, German Cancer

Research Center, Germany

Manel Juan, Hospital Clínic, Spain

*Correspondence:

Alison Mary Rich, Faculty of

Dentistry, Sir John Walsh Research

Institute, University of Otago, PO Box

647, Dunedin 9054, New Zealand

e-mail: alison.rich@otago.ac.nz
It is becoming increasingly apparent that the tumor microenvironment plays an important role in the progression of cancer. The microenvironment may promote tumor cell survival and proliferation or, alternatively may induce tumor cell apoptosis. Toll-like receptors (TLRs) are transmembrane proteins, expressed on immune cells and epithelial cells, that recognize exogenous and endogenous macromolecules. Once activated, they initiate signaling pathways leading to the release of cytokines and chemokines, which recruit immune cells inducing further cytokine production, the production of angiogenic mediators and growth factors, all of which may influence tumor progression. This paper examines the actions of TLRs in carcinogenesis with particular emphasis on their role in oral squamous cell carcinoma.

Keywords: toll-like receptors, TLR, NF-kB, oral squamous cell carcinoma

\section{INTRODUCTION}

Toll-like receptors (TLRs) are cell surface or intracellular transmembrane proteins that are expressed on sentinel cells of the immune system such as macrophages and dendritic cells. In addition, they are present on non-immune cells such as keratinocytes of skin (1) and oral mucosa (2), gastrointestinal (3), and female reproductive tract lining (4). On these lining epithelia, TLRs act as sensors where they recognize pathogens and are activated when the epithelium is disturbed. Microbial pathogens are characterized by specific arrangements of molecules known as pathogen-associated molecular patterns (PAMPs), which can be recognized by pattern-recognition receptors (PRRs), including TLRs. TLRs are capable of recognizing bacterial, viral, fungal, and protozoal components. While their role as PRRs is important in host defense, it is their ability to regulate innate and adaptive immune responses via information from surface epithelial cells that is their most potent role, along with their ability to recruit immune cells (5).

Once activated, TLRs trigger co-ordinated expression of genes involved in specific signaling pathways in the regulation of innate and adaptive immunity and tissue repair and regeneration. Their cytoplasmic domain has extensive homology with the interleukin (IL)-1 receptor family and is known as the Toll-IL receptor (TIR) domain (6). With binding of ligand to TLRs, there is activation of signaling transduction pathways involving TIR with coupling to adaptor molecules including myeloid differentiation factor 88 (MyD88), TIR domain-containing protein (TIRAP), and TIR domain-containing adaptor inducing interferon- $\beta$-related adaptor molecule (TRAM). This potentially leads to the activation of two main pathways, the MyD88-dependent (used by all TLRs except TLR3) and the MyD88-independent TRAM/TRIF pathway (used by TLR3 and some signals of TLR4) (5). Signaling through the MyD88 pathway leads to activation and translocation from the cytoplasm to the nucleus of the transcription factor nuclear factor- $\mathrm{kB}(\mathrm{NF}-\kappa \mathrm{B})$. There it binds to the promoter region of a variety of immune and inflammatory genes leading to the transcription of inflammatory and antiinflammatory cytokine genes, e.g., tumor necrosis factor (TNF)$\alpha$ and IL-6 $(3,4,7)$. Activation of the TRAM/TRIF pathway leads to the production of type 1 interferons. In this manner, TLRs regulate the production of cytokines, opsonization, coagulation cascades, complement activation, and upregulation of co-stimulatory molecules on antigen presenting cells $(4,8,9)$. Alteration to TLR genes, as occurs with single-nucleotide polymorphisms (SNPs), may interfere with the function of TLRs and shift the balance of the cytokines produced (10). A further important function of TLRs is the induction of apoptosis through the expression of anti-apoptotic proteins and apoptosis inhibitors (11).

Initially, study of TLRs in pathology was concentrated on their association with microbial pathogens. It is increasingly apparent that TLRs also recognize damage/danger-associated molecular patterns (DAMPs), endogenous molecules released from damaged and dying cells. DAMPs include heat shock proteins (HSP), nucleic acids, fibrinogen, and high-motility group box-1 protein (HMGB1) $(3,12,13)$. DAMPs can be released from cells that have been affected by various stimuli and have entered a potentially neoplastic phase, as well as from cells that have undergone malignant transformation $(14,15)$. This has led to a large number of studies investigating the role of TLRs in the pathogenesis of a range of malignant neoplasms. The association of TLRs with neoplasia will be discussed below, with particular emphasis on two points: (a) how this information can be used to advance our knowledge of the association between TLRs, inflammation, and cancer, particularly oral squamous cell carcinoma (OSCC) and (b) how it can be used to develop new therapeutic strategies. 


\section{INFLAMMATION, TLRS, AND CANCER}

Infection is an important cause of cancer, causing approximately one in five malignancies worldwide $(16,17)$. Infection with the bacterium Helicobacter pylori leads to an elevated risk of developing gastric adenocarcinoma and gastric lymphoma, infection with particular types of human papilloma virus (HPV) leads to cervical cancer, tonsillar carcinoma, and some cases of OSCC, and chronic hepatitis B and C infections leads to hepatocellular carcinoma (1619). The herpesvirus, Epstein-Barr virus (EBV), is implicated in a range of malignancies including Burkitt's lymphoma, Hodgkin lymphoma, and nasopharyngeal carcinoma, and another member of the herpesvirus family, human herpesvirus 8 , is a causal factor in Kaposi sarcoma $(17,18)$. The response of TLRs to these infections is crucial to the evolution of the infection and possibly to the transformation to malignancy, but a full review of infection and cancer is beyond the scope of this review. Instead, we intend to concentrate on the role of TLRs in tumor development, whether or not the tumor was associated with prior infection. The modulation of the inflammatory process by TLRs is a key factor in tumor development and progression, inducing both tumor-promoting and anti-tumor responses $(15,20)$. TLRs have also been shown to play a crucial role in tissue repair and regeneration following injury, particularly in relation to epithelial regeneration and myofibroblast activation (20-22) These processes may be mediated by TLRs providing pro-survival signals and by preventing apoptosis and hence may dictate the balance between satisfactory and maladaptive wound healing $(21,22)$.

Genetic disruption of TLRs and adaptor molecules of the TLR pathway has been associated with tumor development and progression in mice $(23,24)$. TLRs mediate both pro- and antitumorogenic pathways, the so-called double-edged sword (25, 26) - see Figure 1. DAMP activation of TLRs expressed on tumor cells initiates cascades that mediate the release of cytokines and chemokines from the tumor cells which, in turn, recruit immune cells leading to upregulation of NF- $\mathrm{KB}$ signaling and subsequent release of additional cytokines, pro-angiogenic mediators, growth factors, and anti-apoptotic proteins that continue to promote tumor survival and progression $(15,20,27)$. It should be noted, however, that the role TLRs play in relation to apoptosis is complex and variable with evidence that they can prevent apoptosis, but also have pro-apoptotic activity through a range of mechanisms $(28,29)$.

The nuclear transcriptional factor NF- $\mathrm{BB}$ is constitutively expressed in many human cancers $(30,31)$, and its signaling pathway has a critical role in carcinogenesis $(32,33)$. Mutations in NF- $\mathrm{KB}$ signaling molecules have been reported in a range of malignancies, including human B-cell lymphomas (34). NF- $\kappa$ B is likely to be linked to this process through its ability to induce expression of adhesion molecules, MMPs, and pro-inflammatory cytokines, which creates a microenvironment favorable for cancer cell survival $(7,32)$. A potential feedback loop between pro-inflammatory cytokines such as TNF- $\alpha$ and NF- $\kappa B$ has been suggested and this links the role of NF- $\mathrm{KB}$ in inflammation and cancer $(32,35)$. It has also been suggested that NF- $\mathrm{KB}$ contributes to genomic instability through its anti-apoptotic activities, in addition to the suppression of apoptosis in tumor cells, which promotes tumor cell survival $(36,37)$. The NF- $\mathrm{kB}$ signaling pathway is an essential antiapoptotic pathway that has been shown to control the expression of anti-apoptotic genes and restrict the activation of pro-apoptotic pathways (20).

It has been suggested that the amplitude and duration of TLR activation may be instrumental in tumor development, with chronic low-grade activation favoring a tumor-promoting proinflammatory state and with high dose therapeutically induced TLR activation favoring an anti-tumor response (20). Various TLRs play different roles in carcinogenesis. TLR4 shows

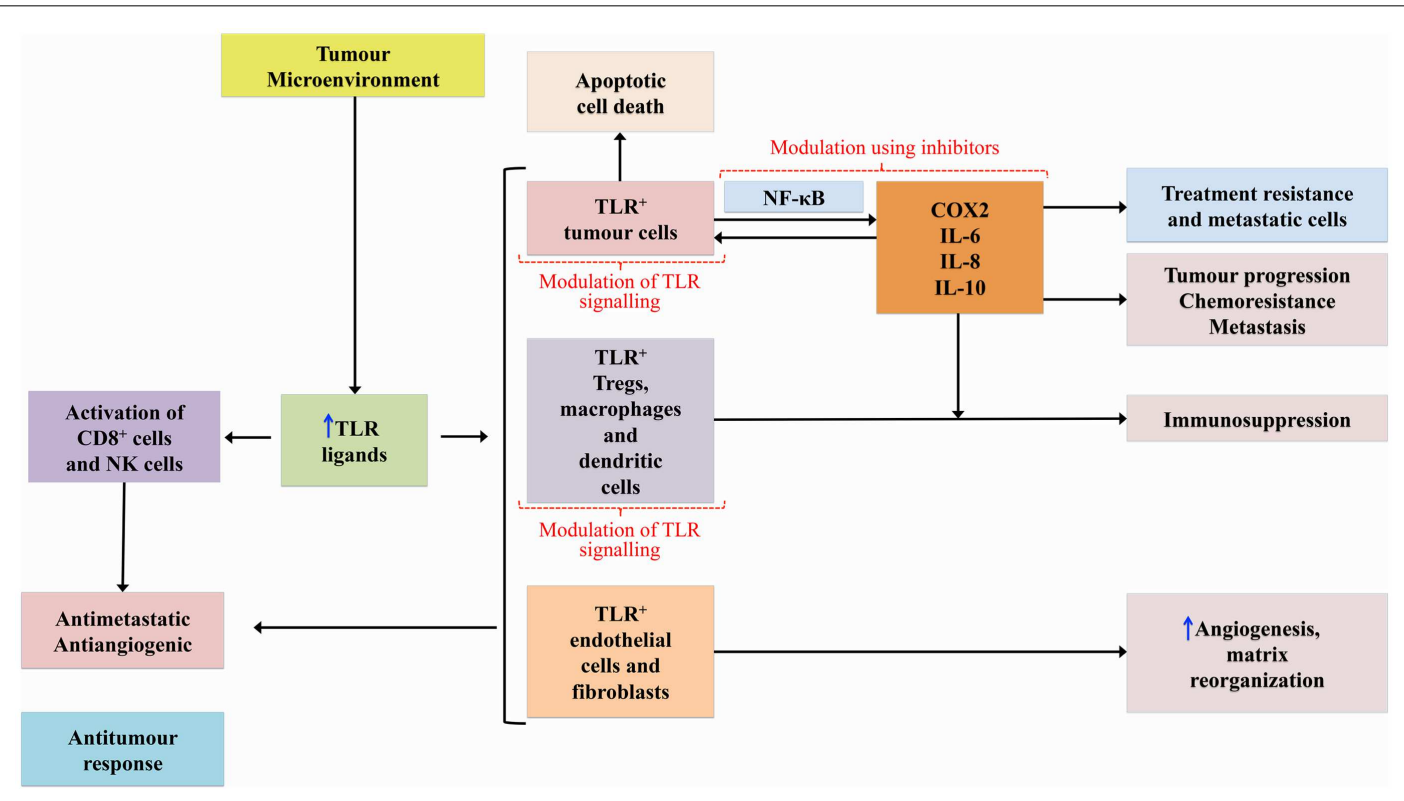

FIGURE 1 | Diagram showing how TLRs can mediate pro- and anti-tumor pathways. 
pro-tumorogenic effects, with mice deficient in TLR4 at reduced risk of developing gastrointestinal and hepatocellular cancer (23, 38). This effect has been shown to be due to augmentation of the inflammatory response via activation of the NF- $\kappa \mathrm{B}$, and cyclooxygenase (Cox)-2/prostaglandin E2 signaling pathways $(23,38)$. The TLR4 pro-tumorogenic activity is mainly due to its expression on tumor cells where it mediates resistance of tumor cells to damage induced by cytotoxic T lymphocytes $(25,37)$, but triggering of TLR4 expressed on immune cells is also important in tumor development and progression (37). Release of HSP from tumor cells can lead to activation of TLR4 on tumor-associated macrophages, in turn mediating NF- $\kappa \mathrm{B}$ activation of tumor cells (39). While TLR4 is predominately pro-tumorogenic, it can induce the production of interferons contributing to an anti-tumor response (37).

Both TLR3 and TLR5 are also pro-tumorogenic with their signals mediating tumor invasion and metastasis by enhancing cell migration, but, like TLR4, also have an anti-cancer effect in some situations $(14,40,41)$. TLR9 expressed on tumor cells has been associated with increased cell proliferation and increased invasion potential $(42,43)$. On the other hand, TLR2 signaling suppressed cancer development and assisted tumor regression (37). Lack of TLR2 led to increased cell proliferation and decreased apoptosis in a mouse model of colorectal cancer (24). The mechanism by which TLR2 induces tumor suppression is thought to be mediated through tumor-derived HMGB1, which activates TLR2 in dendritic cells in the tumor microenvironment, leading to tumor regression (44). While most reports describe the antitumor functions of TLR2, opposing results have been reported in a context-dependent manner with TLR2 playing an important tumor-promoting role in gastric cancer $(20,45,46)$.

\section{ASSOCIATION OF TLRS WITH ORAL CANCER}

Oral and pharyngeal cancer is the sixth most common cancer in the world, with oral cancer having an annual estimated incidence of approximately 275,000 globally and with two-thirds of cases occurring in developing countries (47). Despite advances in diagnosis and improved treatment strategies, OSCC continues to have a poor 5-year survival rate, and conventional treatment modalities of surgery and radiotherapy are associated with significant morbidity (48). OSCC, like other cancers, develops in an immune cell-rich environment, where inflammatory cells in the tumor microenvironment establish an anti-tumor response by secreting pro-inflammatory cytokines. At the same time, the cancer cells may induce various mechanisms suppressing the anti-tumor response, such as regulating a network of suppressive cytokines and the recruitment of suppressive regulatory T-cells (Tregs). Studies have shown TLRs, particularly TLR2, play a role in Treg expansion and their suppressive capacity (49). More keratinocytes in OSCC expressed TLR2 than keratinocytes in control epithelium (50). Further research in our laboratory has confirmed the presence of TLR2 ${ }^{+}$cells within the OSCC microenvironment (51). The cells that were expressing TLR2 were large and morphologically consistent with macrophages or DC (Figure 2). The presence of $\mathrm{TLR}^{+}{ }^{+} \mathrm{FoxP}^{+}$cells within the OSCC immune cell infiltrate was noted, an observation previously unreported in OSCC. This is important, particularly in relation to cancer immumotherapy. Cells expressing TLRs could potentially be modulated to shift

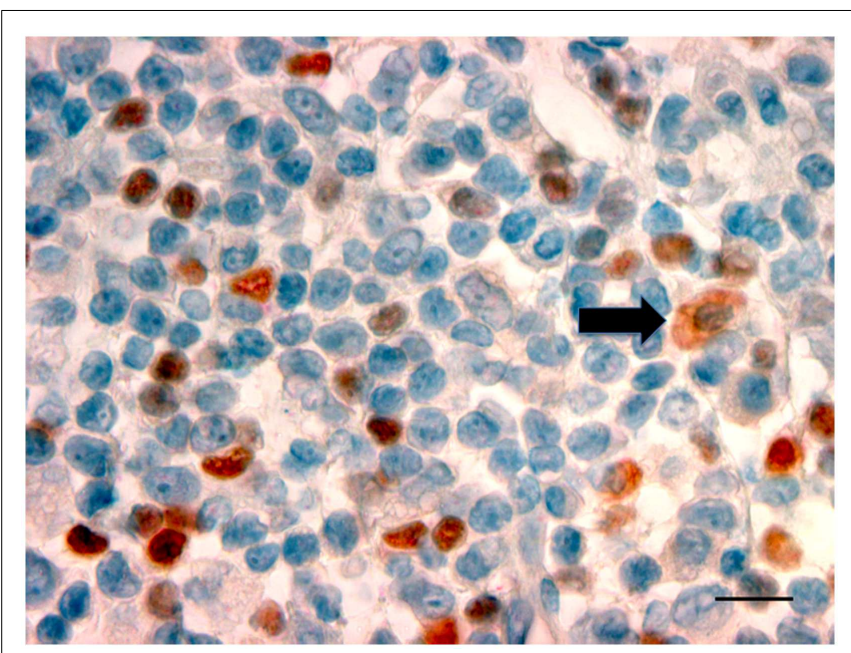

FIGURE 2 | Photomicrograph showing TLR2+ cells with a dusky red cell membrane and cytoplasmic staining (black arrow) with the morphology of macrophages in OSCC $(\times 100$, bar: $100 \mu \mathrm{m})$

the environment toward a Th1 environment, thus stimulating the pro-inflammatory process.

Head and neck cancer cell lines and OSCC tissue specimens were found to express TLR3, and this was associated with high levels of expression and activity of NF- $\mathrm{B}$ (40, 41, 52). Inhibition of TLR3 by siRNA resulted in decreased expression of the NF- $\mathrm{B}$-regulated oncogene $\mathrm{c}-\mathrm{myc}$ and decreased cell proliferation (53). Stimulation of TLR3 ${ }^{+}$OSCC tumor cells promoted their migration, and TLR3 expression was found to be significantly correlated with poor differentiation and perineural invasion in OSCC (40). Further, activation of TLR3 was found to induce apoptosis in OSCC cells, most likely mediated by activation of the IRF/IFN- $\beta$ signaling pathway (41).

TLR4 and MyD88 were expressed in human OSCC cell lines and expression level correlated with tumor differentiation, with higher expression in more well-differentiated carcinomas (54). Expression of TLR4 increased with increasing degrees of oral epithelial dysplasia (55) and distribution of TLR4 extended from the basal layer through the stratum spinosum as dysplasia progressed.

TLR5 expression was more pronounced in tongue cancer cells than in adjacent apparently normal epithelium and high expression levels of TLR5 predicted a poorer prognosis (14). While, overall, there was relatively little TLR9 expression in dysplastic oral tissue, there was significantly more than in normal oral mucosa (55) and increased expression of TLR9 had earlier been found to correlate with increased tumor cell proliferation in OSCC $(56,57)$. Subsequent reports suggested that TLR9 directly promoted cancer cell invasion (58).

\section{THERAPEUTIC POSSIBILITIES}

Since advances in conventional treatments have not appreciably increased the survival rate of OSCC (48), attention has turned to immunotherapy including investigation of drugs that interfere with the NF- $\mathrm{B}$ and TLR signaling pathways. Interference with these pathways has implications for many of the important steps 
in carcinogenesis including the relationship between $\mathrm{TLR}^{+}$cells and regulatory T-cells, and subsequent cytokine production, the effects on dendritic cells and macrophages, the effects on apoptosis and on cell proliferation. Acetylsalicylic acid has been shown to reduce the long-term risk of developing some cancers, and, while the precise mechanisms of action remain uncertain, there is evidence that modulation of the NF- $\kappa \mathrm{B}$ signal transduction pathway by aspirin and other non-steroidal anti-inflammatory agents is an important mechanism in inducing apoptosis in neoplastic epithelial cells $(59,60)$. Meyer et al. (33) found aspirin and another COX-2 inhibitor, celecoxib inhibited NF- $\mathrm{B}$ in head and neck cancer cell lines. Both selective and non-selective COX-2 inhibitors reduced cancer incidence and invasion score in an animal model of experimental oral carcinogenesis, although the potential mechanisms of actions of the drugs were not discussed in detail (61). Drugs other than COX inhibitors have been shown to interfere with the NF- $\kappa \mathrm{B}$ pathway in various malignancies, e.g., glucocorticoids, while being pro-apoptotic in leukemia and lymphomas, have been found to enhance survival of some breast cancer cell lines through promoting NF- $\kappa \mathrm{B}$ transcriptional activity leading to upregulation of $c-M y c$ and enhanced anti-apoptotic function (62, 63). Sulfasalazine can act as a NF- $\mathrm{B}$ inhibitor leading to reduced proliferation and enhanced apoptosis of esophageal cancer cell lines (64) and has be shown to induce autophagic cell death in oral cancer cell lines, although this was thought to be mediated via Akt and ERK pathways (65).

It is likely that at least some of the effects on NF-кB are mediated through various TLR pathways. TLR4 induced resistance to cisplatin-induced apoptosis in OSCC cell lines (54). The authors suggested that activation of TLR 4 and its signaling pathways was a mechanism to explain the resistance that develops in patients with OSCC, after a good initial response to that drug. The potential use of the immunostimulatory properties of TLR agonists, particularly TLR2, TLR3, TLR4, TLR7/8, and TLR9, has been investigated in cancer immunotherapy (66). Sutmuller and colleagues (49) showed that TLR2 controls the expansion and suppression of Tregs by directly acting on these cells. They also showed that there was a temporary loss of Treg suppressive function when bound to a TLR2 ligand; concurrently, this could also induce the proliferation of $\mathrm{CD} 4{ }^{+} \mathrm{CD} 25^{+}$Tregs. Subsequently, it was shown that TLR2 agonists enhanced the suppressive effect of Tregs (67). This observation may explain in part the failure of some immunotherapies, in particular, the use of TLR agonists as anti-cancer treatment. By inducing apoptosis, necrosis, and activating immune and dendritic cells, TLR agonists induce an anti-tumor effect (68). Topical imiquimod, a synthetic TLR7 agonist, that has been shown to induce temporary regression of breast cancer in an animal model (69) and has had some success in the management of varying types of dysplastic skin lesions and superficial skin cancers $(70,71)$. It has been shown to reduce the degree of dysplasia in a mouse model of oral cancer (although there was no long-term follow-up) (72) and in OSCC cell lines (73).

Although much anticipated, the outcome of TLR agonist therapeutic trials has been disappointing (74). Clinical studies with TLR agonists have shown expansion of Tregs within the tumor environment, which may enhance tumor progression, although some trials have shown reduction in tumor size $(69,75)$. This has earned TLRs the connotation of a "double-edged sword" by most workers who investigated their functionality $(76,77)$. Hence, the therapeutic use of TLR agonists needs to be undertaken with caution. TLR antagonists are structural analogs of agonists, which bind to TLRs and do not induce signal transduction. This prevents the agonistic action of TLR ligands responsible for the induction of inflammatory responses $(78,79)$. These agents can be used to gain a greater understanding of the effectiveness of TLR agonist therapy in animal models of cancer.

To overcome the "double-edged sword," manipulation of the "un-touched" TLR ${ }^{+}$cells within the OSCC tumor microenvironment is required. The key factors lie in the balance of the cytokine network within the tumor environment. It is crucial to look into the expression of various cytokines at different stages of OSCC.

Inhibition of NF- $\mathrm{B}$ in head and neck cancer cell lines was associated with downregulation of TLR3 and decreased levels of IL-6 and IL- 8 and the expected shift to a $\mathrm{T}_{\mathrm{H}} 2$ microenvironment, typical in head and neck squamous cell carcinomas did not occur (33). Modulation of macrophages or DCs using the cytokine network is necessary to overcome potential immune suppression, before they are recruited to become tolerogenic cells. The administration of agents that interfered with TLR3 signaling in a mouse model of lung cancer led to tumor regression by converting tumorsupporting macrophages to tumor suppressors (80). Again, the presence of "un-touched" TLR $^{+}$macrophages supports the theory that reversal or "resurgence" by the immune system is important in fighting back against the tumor escape mechanisms.

The association of TLRs with tumor cell proliferation is another potential area for therapeutic intervention. TLR3 (52) and TLR9 (56) have been associated with cell proliferation in head and neck cancer, and Ruan et al. (58) suggested that the use of anti-TLR9 agents may reduce tumor cell proliferation in OSCC as well as reducing metastatic potential.

Although complete molecular mechanisms remain to be determined, there are a variety of TLR pathways that may provide therapeutic targets for the management of OSCC.

\section{REFERENCES}

1. Baker BS, Ovigne J-M, Powles AV, Corcoran S, Fry L. Normal keratinocytes express toll-like receptors (TLRs) 1, 2 and 5: modulation of TLR expression in chronic plaque psoriasis. Br J Dermatol (2003) 148:670-9. doi:10.1046/j.13652133.2003.05287.x

2. Sugawara Y, Uehara A, Fujimoto Y, Kusomoto S, Fukase K, Shibata K, et al. Toll-like receptors, NOD1 and NOD2 in oral epithelial cells. J Dent Res (2006) 85:524-9. doi:10.1177/154405910608500609

3. Carvalho FA, Aitken JD, Vijay-Kumar M, Gewirtz AT. Toll-like receptor-gut microbiota interactions:perturb at your own risk! Ann Rev Physiol (2012) 74:177-98. doi:10.1146/annurev-physiol-020911-153330

4. Nasu K, Narahara H. Pattern recognition via the toll-like receptor system in the human female genital tract. Mediators Inflamm (2010) 2010:976024. doi:10.1155/2010/976024

5. Basith S, Manavalan B, Yoo TH, Kim SG, Choi S. Roles of toll-like receptors in cancer: a double-edged sword for defense and offense. Arch Pharm Res (2012) 35:1297-316. doi:10.1007/s12272-012-0802-7

6. Xu Y, Tao X, Shen B, Horng T, Medzhitov R, Manley JL, et al. Structural basis for signal transduction by the toll/interleukin-1 receptor domains. Nature (2000) 408:111-5. doi:10.1038/35047056

7. Newton K, Dixit VM. Signaling in innate immunity and inflammation. Cold Spring Harb Perspect Biol (2012) 4. doi:10.1101/cshperspect.a006049

8. Akira S, Takeda K, Kaisho T. Toll-like receptors: critical proteins linking innate and acquired immunity. Nat Immunol (2001) 2:675-80. doi:10.1038/90609 
9. Medzhitov R. Toll-like receptors and innate immunity. Nat Rev Immunol (2001) 1:135-45. doi:10.1038/35100529

10. Yang Z, Dai Q, Gu Y, Guo QX, Gong L. Cytokine and chemokine modification by toll-like receptor polymorphisms is associated with nasopharyngeal carcinoma. Cancer Sci (2012) 103:653-8. doi:10.1111/j.1349-7006.2012.02210.x

11. Ioannou S, Voulgarelis M. Toll-like receptors, tissue injury, and tumourigenesis. Mediators Inflamm (2010) 2010:581837. doi:10.1155/2010/581837

12. Miyake K. Innate immmune sensing of pathogens and danger signals by cell surface toll-like receptors. Semin Immunol (2007) 19:3-10. doi:10.1016/j.smim. 2006.12.002

13. Kawai T, Akira S. The role of pattern-recognition receptors in innate immunity: update on toll-like receptors. Nat Immunol (2010) 11:373-84. doi:10.1038/ni. 1863

14. Kauppila JH, Mattila AE, Karttunen TJ, Salo T. Toll-like receptor 5 (TLR5) expression is a novel predictive marked for recurrence and survival in squamous cell carcinoma of the tongue. Br J Cancer (2013) 108:638-43. doi:10.1038/bjc. 2012.589

15. Ridnour LA, Cheng RYS, Switzer CH, Heinecke JL, Ambs S, Glynn S, et al. Molecular pathways: toll-like receptors in the tumor microenvironment-poor prognosis or new therapeutic opportunity. Clin Cancer Res (2013) 19:1340-6. doi:10.1158/1078-0432.CCR-12-0408

16. Parkin DM. The global health burden infection-associated cancers in year 2002. Int J Cancer (2006) 118:3030-44. doi:10.1002/ijc.21731

17. de Martel C, Franceschi S. Infections and cancer: established associations and new hypotheses. Crit Rev Oncol Hematol (2009) 70:183-94. doi:10.1016/j. critrevonc.2008.07.021

18. Pagano JS, Blaser M, Buendia M-A, Damania B, Khalili K, Raab-Traub N, et al. Infectious agents and cancer: criteria for a causal relation. Semin Cancer Biol (2004) 14:453-71. doi:10.1016/j.semcancer.2004.06.009

19. Ryerson AB, Peters ES, Coughlin SS, Chen VW, Gillison ML, Reichman ME, et al. Burden of potentially human papillomavirus-associated cancers of the oropharynx and oral cavity in the US, 1998-2003. Cancer (2008) 113:2901-9. doi:10.1002/cncr.23745

20. Pradere J-P, Dapito DH, Schwabe RF. The yin and yang of toll-like receptors in cancer. Oncogene (2014) 33:3485-95. doi:10.1038/onc.2013.302

21. Rakoff-Nahoum S, Medzhitov R. Role of toll-like receptors in tissue repair and tumorigenesis. Biochemistry (Moscow) (2008) 73:555-61. doi:10.1134/ S0006297908050088

22. Huebener P, Schwabe RF. Regulation of wound healing and organ fibrosis by toll-like receptors. Biochim Biophys Acta (2013) 1832:1005-17. doi:10.1016/j. bbadis.2012.11.017

23. Fukata M, Chen A, Vamadevan AAS, Cohen J, Breglio K, Krishnareddy S, et al. Toll-like receptor-4 promotes the development of colitis-associated colorectal tumors. Gastroenterology (2007) 133:1869-81. doi:10.1053/j.gastro.2007.09. 008

24. Lowe EL, Crother TR, Rabizadeh S, Hu B, Wang H, Chen S, et al. Toll-like receptor 2 signaling protects mice from tumor development in a mouse model of colitisinduced cancer. PLoS One (2010) 5:e13027. doi:10.1371/journal.pone.0013027

25. Huang B, Zhao J, Li H, He KL, Chen Y, Chen SH, et al. Toll-like receptors on tumor cells facilitate evasion of immune surveillance. Cancer Res (2005) 65(12):5009-14. doi:10.1158/0008-5472.CAN-05-0784

26. He W, Liu Q, Wang L, Chen W, Li N, Cao X. TLR4 signaling promoted immune escape of human lung cancer cells by inducing immunosuppressive cytokines and apoptosis resistance. Mol Immunol (2007) 44:2850-9. doi:10. 1016/j.molimm.2007.01.022

27. Sato Y, Gato Y, Narita N, Hoon DS. Cancer cells expressing toll-like receptors and the tumor microenvironment. Cancer Microenviron (2009) 2(Suppl):205-14. doi:10.1007/s12307-009-0022-y

28. Ruckdeschel K, Pfaffinger G, Haase R, Sing A, Weighardt H, Holzmann B, et al. Signaling of apoptosis through TLRs critically involves toll/IL-1 receptor domain-containing adapter inducing IFN-beta, but not MyD88, in bacteriainfected murine macrophages. J Immunol (2004) 173:3320-8. doi:10.4049/ jimmunol.173.5.3320

29. Hsu LC, Park JM, Zhang K, Luo JL, Maeda S, Kaufman RJ, et al. The protein kinase PKR is required for macrophage apoptosis after activation of toll-like receptor 4. Nature (2004) 428:341-5. doi:10.1038/nature02405

30. Williams JL, Ji P, Ouyang N, Liu X, Rigas B. NO-donating aspirin inhibits the activation of NF-кB in human cell lines and Min mice. Carcinogenesis (2008) 29:390-7. doi:10.1093/carcin/bgm 275
31. Wang JQ, Jeelall YS, Ferguson LL, Horikawa K. Toll-like receptors and cancer: MYD88 mutation and inflammation. Front Immunol (2014) 5:367. doi:10.3389/ fimmu.2014.00367

32. Kipanyula MJ, Etet PFS, Vecchio L, Farahna M, Nukenine EN, Kamdje AHN Signaling pathways bridging microbial-triggered inflammation and cancer. Cell Signal (2013) 25:403-16. doi:10.1016/j.cellsig.2012.10.014

33. Meyer C, Pries R, Wollenberg B. Established and novel NF-кB inhibitors lead to downregulation of TLR3 and the proliferation and cytokine secretion in HNSCC. Oral Oncol (2011) 47:818-26. doi:10.1016/j.oraloncology.2011.06.010

34. Giulino L, Mathew S, Ballon G, Chadburn A, Barouk S, Antoneicelli G. A20 (TNFAIP3) genetic alterations in EBV-associated AIDS-related lymphoma. Blood (2011) 117:4852-4. doi:10.1182/blood-2010-10-310995

35. Pikarsky E, Porat RM, Stein L, Abramovitch R, Amit S, Kasem S. NF-kappaB functions as a tumour promoter in inflammation-associated cancer. Nature (2004) 431:461-6. doi:10.1038/nature02924

36. Karin M, Cao Y, Greten FR, Li ZW. NF-kappaB in cancer: from innocent bystander to major culprit. Nat Rev Cancer (2002) 2:301-10. doi:10.1038/nrc780

37. Yu L, Wang L, Chen S. Dual character of toll-like receptor signalling: protumorigenic effects and anti-tumor functions. Biochim Biophys Acta (2013) 1835:144-54. doi:10.1016/j.bbcan.2012.10.006

38. Yu LX, Yan HX, Liu Q, Yang W, Wu HP, Dong W, et al. Endotoxin accumulation prevents carcinogen-induced apoptosis and promotes liver tumorigenesis in rodents. Hepatology (2010) 52:1322-33. doi:10.1002/hep.23845

39. Lee $\mathrm{CH}, \mathrm{Wu} \mathrm{CL}$, Shiau AL. Toll-like receptor 4 signalling promotes tumor growth. J Immunother (2010) 33:73-82. doi:10.1097/CJI.0b013e3181b7a0a4

40. Chuang H-C, Huang C-C, Chien C-Y, Chuang J-H. Toll-like receptor 3mediated tumor invasion in head and neck cancer. Oral Oncol (2012) 48:226-32. doi:10.1016/j.oraloncology.2011.10.008

41. Luo Q, Hu S, Yan M, Sun Z, Chen W, Chen F. Activation of toll-like receptor 3 induces apoptosis of oral squamous cell carcinoma cells in vitro and in vivo. Int J Biochem Cell Biol (2012) 44:1266-75. doi:10.1016/j.biocel.2012.04.025

42. Tanaka J, Sugimoto K, Shiraki K, Tameda M, Kusagawa S, Norjiri K, et al. Functional cell surface expression of toll-like receptor 9 promotes cell proliferation and survival in human hepatocellular carcinomas. Int J Oncol (2010) 37:805-14. doi:10.3892/ijo_00000730

43. Ren T, Wen ZK, Liu ZM, Liang ZI, Guo ZL, Xu L. Functional expression of TLR9 is associated with metastatic potential of human lung cancer cell: functional active role of TLR9 on tumor metastasis. Cancer Biol Ther (2007) 6:1704-9. doi:10.4161/cbt.6.11.4826

44. Curtin JF, Liu N, Candolfi M, Xiong W, Assi H, Yagiz K, et al. HMGB1 mediates endogenous TLR2 activation and brain tumor regression. PLoS Med (2009) 6:e10. doi:10.1371/journal.pmed.10000010

45. Xie W, Huang Y, Xie W, Guo A, Wu W. Bacteria peptidoglycan promoted breast cancer cell invasiveness and adhesiveness by targeting toll-like receptor 2 in the cancer cells. PLoS One (2010) 5:e10850. doi:10.1371/journal.ponw.0010850

46. Tye H, Kennedy CL, Najdovska M, McLeod L, McCormack W, Hughes N, et al. STAT-3 driven upregulation of TLR2 promotes gastric tumorigenesis independent of tumor inflammation. Cancer Cell (2012) 22:466-78. doi:10.1016/j.ccr. 2012.08.010

47. Warnakulasuriya S. Global epidemiology of oral and oropharyngeal cancer. Oral Oncol (2009) 45:309-16. doi:10.1016/j.oraloncology.2008.06.002

48. Scully C, Bagan J. Oral squamous cell carcinoma: overview of current understanding of aetiopathogenesis and clinical implications. Oral Dis (2009) 15:388-99. doi:10.1111/j.1601-0825.2009.01563.x

49. Sutmuller RPM, Den Brok MHMGM, Kramer M, Bennink EJ, Toonen LWJ, Kullberg B-J, et al. Toll-like receptor 2 controls expansion and function of regulatory T cells. J Clin Invest (2006) 116:485-94. doi:10.1172/JCI25439

50. Ng LK, Rich AM, Hussaini HM, Thomson WM, Fisher AL, Horne LS, et al. Toll-like receptor 2 is present in the microenvironment of oral squamous cell carcinoma. Br J Cancer (2011) 104:460-3. doi:10.1038/sj.bjc.6606057

51. Mohd Hussaini H. Immune Responses In Primary OSCC and Lymph Node Metastasis. (Thesis, Doctor of Philosophy). University of Otago. Available from: http://hdl.handle.net/10523/4289

52. Pries R, Hogrefe L, Xie L, Frenzel H, Brocks C, Ditz C, et al. Induction of cMyc-dependent cell proliferation through toll-like receptor 3 in head and neck cancer. Int J Mol Med (2008) 21:209-15. doi:10.3892/ijmm.21.2.209

53. Pries R, Wulff S, Wollenberg B. Toll-like receptor modulation in head and neck cancer. Crit Rev Immunol (2008) 28:201-13. doi:10.1615/CritRevImmunol.v28. i3. 20 
54. Sun Z, Luo Q, Ye D, Chen W, Chen F. Role of toll-like receptor 4 on the immune escape of human oral squamous cell carcinoma and resistance of cisplatin-induced apoptosis. Mol Cancer (2012) 11:33-44. doi:10.1186/14764598-11-33

55. Kotrashetti VS, Hayak R, Bhat K, Hosmani J, Somannavar P. Immunohistochemical expression of TLR4 and TLR9 in various grades of oral epithelial dysplasia and squamous cell carcinoma, and their roles in tumor progression: a pilot study. Biotech Histochem (2013) 88:311-22. doi:10.3109/10520295.2013.785592

56. Ruan M, Zun Z, Li S, Yang W, Wang L, Zhang C. Increased expression of toll-like receptor-9 has close relation with tumour cell proliferation in oral squamous cell carcinoma. Arch Oral Biol (2011) 56:877-84. doi:10.1016/j.archoralbio.2011.01. 010

57. Ruan M, Li S, Yang W, Liu S, Ow A, Wang L, et al. Toll-like receptor-9 agonists increase cyclin D1 expression partly through activation of activator protein1 in human oral squamous cell carcinoma. Cancer Sci (2012) 103:1938-45. doi:10.1111/j.1349-7006.2012.02394.x

58. Ruan M, Zhang Z, Li S, Yan M, Liu S, Yang W, et al. Activation of toll-like receptor-9 promotes cellular migration via upregulating MMP-2 expression in oral squamous cell carcinoma. PLoS One (2014) 9:e92748. doi:10.1371/journal. pone.0092748

59. Stark LA, Reid K, Sansom OJ, Din FV, Guichard S, Mayer I, et al. Aspirin activates the NF- $\mathrm{B}$ signalling pathway and induces apoptosis in intestinal neoplasia in two in vivo models of human colorectal cancer. Carcinogenesis (2007) 28:968-76. doi:10.1093/carcin/bgl220

60. Dovizio M, Tacconelli S, Sostres C, Ricciotti E, Patrignani P. Mechanistic and pharmacological issues of aspirin as an anticancer agent. Pharmaceuticals (Basel) (2012) 5:1346-71. doi:10.3390/ph5121346

61. McCormick DL, Phillips JM, Horn TL, Johnson WD, Steele VE, Lubet RA. Overexpression of cyclooxygenase- 2 in rat oral cancers and prevention of oral carcinogenesis in rats by selective and nonselective COX inhibitors. Cancer Prev Res (Phila) (2010) 3:73-81. doi:10.1158/1940-6207.CAPR-09-0151

62. Ling J, Kumar R. Crosstalk between NF-кB and glucocorticoid signalling: a potential target of breast cancer therapy. Cancer Lett (2012) 322:119-26. doi:10.1016/j.canlet.2012.02.033

63. Khan S, Lopez-Dee Z, Kumar R, Ling J. Activation of NF-кB is a novel mechanism of pro-survival activity of glucocorticoids in breast cancer cells. Cancer Lett (2013) 337:90-5. doi:10.1016/j.canlet.2013.05.020

64. Li B, Li YY, Tsao SW, Cheung AL. Targeting NF-kappaB signaling pathway suppresses tumor growth, angiogenesis, and metastasis of human esophageal cancer. Mol Cancer Ther (2009) 9:2635-44. doi:10.1158/1535-7163.MCT-09-0162

65. Han HY, Kim H, Jeong SH, Lim DS, Ryu MH. Sulfasalazine induces autophagic cell death in oral cancer cells via Akt and ERK pathways. Asian Pac J Cancer Prev (2014) 15:6939-44. doi:10.7314/APJCP.2014.15.16.6939

66. Adams S. Toll-like receptor agonists in cancer therapy. Immunotherapy (2009) 1:949-64. doi:10.2217/imt.09.70

67. Zanin-Zhorov A, Cahalon L, Tal G, Margalit R, Lider O, Cohen IR. Heat shock protein 60 enhances CD4+CD25+ regulatory $\mathrm{T}$ cell function via innate TLR2 signalling. J Clin Invest (2006) 116:2022-32. doi:10.1172/JCI28423

68. Alexandrescu DT, Ichim TE, Riordan NH, Marincola FM, Di Nardo A, Kabigting FD, et al. Immunotherapy for melanoma: current status and perspectives. J Immunother (2010) 33:570-90. doi:10.1097/CJI.0b013e3181e032e8

69. Lu H, Wagner WM, Gad E, Yang Y, Duan H, Amon LM. Treatment failure of a TLR-7 agonist occurs due to self-regulation of acute inflammation and can be overcome by IL-10 blockade. J Immunol (2010) 184:5360-7. doi:10.4049/jimmunol.0902997

70. Del Rosso JQ. The use of Imiquimod cream for the treatment of actinic keratosis: a status report. Cutis (2005) 76:241-8.

71. Schulze HJ, Cribier B, Requena L, Reifenberger J, Ferrándiz C, Garcia Diez A, et al. Imiquimod 5\% cream for the treatment of superficial basal cell carcinoma: results from a randomized vehicle-controlled phase III study in Europe. $\mathrm{Br} J$ Dermatol (2005) 152:939-47. doi:10.1111/j.1365-2133.2005.06486.x

72. Gkoulioni V, Eleftheriadou A, Yiotakis I, Ferekidou E, Chrisovergis A, Lazaris AC, et al. The efficacy of imiquimod on dysplastic lesions of the oral mucosa: an experimental model. Anticancer Res (2010) 30:2891-6.

73. Ahn M-Y, Kwon S-M, Cheong HH, Park J-H, Lee J, Min S-K, et al. Toll-like receptor 7 agonist, imiquimod, inhibits oral squamous carcinoma cells through apoptosis and necrosis. J Oral Pathol Med (2012) 41:540-6. doi:10.1111/j.16000714.2012.01158.x

74. Guha M. Anticancer TLR agonists on the ropes. Nat Rev Drug Discov (2012) 11:503-5. doi: 10.1038/nrd3775

75. Sfondrini L, Rossini A, Besusso D, Merlo A, Tagliabue E, Mènard S, et al. Antitumor activity of the TLR-5ligand flagellin in mouse models of cancer. J Immunol (2006) 176:6624-30. doi:10.4049/jimmunol.176.11.6624

76. Killeen SD, Wang JH, Andrews EJ, Redmond HP. Exploitation of the tolllike receptor system in cancer: a doubled-edged sword? Br J Cancer (2006) 95:247-52. doi:10.1038/sj.bjc.6603275

77. Conroy H, Marshall NA, Mills KH. TLR ligand suppression or enhancement of Treg cells? A double-edged sword in immunity to tumours. Oncogene (2008) 27:168-80. doi:10.1038/sj.onc.1210910

78. Rezaei N. Therapeutic targeting of pattern-recognition receptors. Int Immunopharmacol (2006) 6:863-9. doi:10.1016/j.intimp.2006.02.005

79. Kanzler H, Barrat FJ, Hessel EM, Coffman RL. Therapeutic targeting of innate immunity with toll-like receptor agonists and antagonists. Nat Med (2007) 13:552-9. doi:10.1038/nm1589

80. Shime H, Matsumoto M, Oshiumi H, Tanaka S, Nakane A, Iwakura Y, et al. Toll-like receptor 3 signaling converts tumor-supporting myeloid cells to tumoricidal effectors. Proc Natl Acad Sci U S A (2012) 109:2066-71. doi:10.1073/pnas. 1113099109

Conflict of Interest Statement: The authors declare that the research was conducted in the absence of any commercial or financial relationships that could be construed as a potential conflict of interest.

Received: 29 June 2014; accepted: 10 September 2014; published online: 24 September 2014.

Citation: Rich AM, Hussaini HM, Parachuru VPB and Seymour GJ (2014) Toll-like receptors and cancer, particularly oral squamous cell carcinoma. Front. Immunol. 5:464. doi: 10.3389/fimmu.2014.00464

This article was submitted to Tumor Immunity, a section of the journal Frontiers in Immunology.

Copyright (C) 2014 Rich, Hussaini, Parachuru and Seymour. This is an open-access article distributed under the terms of the Creative Commons Attribution License (CC $B Y)$. The use, distribution or reproduction in other forums is permitted, provided the original author(s) or licensor are credited and that the original publication in this journal is cited, in accordance with accepted academic practice. No use, distribution or reproduction is permitted which does not comply with these terms. 